\title{
Pulmonary endarterectomy reoperation: frequency, risk factors and outcomes
}

\author{
Stefan Guth, Christoph B. Wiedenroth, Eckhard Mayer \\ Department of Thoracic Surgery, Kerckhoff Heart and Lung Center, Bad Nauheim, Germany \\ Correspondence to: Stefan Guth, MD. Department of Thoracic Surgery, Kerckhoff Heart and Lung Center, Bad Nauheim, Germany. \\ Email: s.guth@kerckhoff-klinik.de.
}

Submitted Aug 04, 2021. Accepted for publication Oct 08, 2021.

doi: 10.21037/acs-2021-pte-140

View this article at: https://dx.doi.org/10.21037/acs-2021-pte-140

\section{Introduction}

Pulmonary endarterectomy (PEA) is the recommended treatment for patients with chronic thromboembolic pulmonary hypertension (CTEPH) (1) and has been adopted in centers across many countries. It has been shown that significant residual or recurrent pulmonary hypertension after PEA carries a poor prognosis. Cannon et al. calculated that a threshold of $36 \mathrm{mmHg}$ and a pulmonary vascular resistance of 5.2 woods units (WU) discriminates an increased mortality and forces clinicians to consider additional treatment options. Therefore, expert PEA surgeons in high volume centers face an increasing number of complex and demanding PEA reoperations (e.g., redo PEA) (2). In this editorial, the option of redo PEA is discussed in the context of the present treatment modalities.

Several factors are important when considering redo surgery in patients with CTEPH. These factors include patients with previous cardiac procedures, patients with primary surgery in less experienced centers and patients with re-embolism or in-situ thrombosis. Patients who have had previous cardiac surgery, such as coronary revascularization or valve repair, are more demanding because of the complexity of re-sternotomy. In contrast surgery on the pulmonary arteries is relatively straightforward if they are previously untouched. The focus here is on patients with previous surgery on the pulmonary arteries. Patients operated on in centers with limited PEA cases, often experience an incomplete clearance of distally located fibrotic material, resulting in residual obstructions and persistent pulmonary hypertension. These patients need further treatment. Meanwhile, the treatment options for CTEPH patients are expanded by pulmonary arterial hypertension (PAH) medication (3) and balloon pulmonary angioplasty (BPA) (4). Decision-making in post PEA patients is now a more demanding process.

The indication for PEA is a challenging and sometimes very individualized process, and the experience level of the multidisciplinary team, especially the surgeon, is crucial. This is even more pronounced in redo PEAs. As reported by other high-volume centers, the main proportion of redo surgery is performed for patients with residual obstructions due to incomplete clearance during the first PEA or (more often) after isolated thrombectomy of centrally located clots $(5,6)$. Reoperations are accompanied by higher risks, with analysis of 46,820 redo coronary artery bypass graft surgeries in the United States revealing a significantly higher mortality, almost twice as high, than in the first operations (7). The risk of redo PEA is also inevitably higher compared to primary PEA. Therefore, patient selection is pivotal to level the risk of mortality if patients are considered for redo PEA. Age, location of the obstruction, hemodynamic impairment and co-morbidities must be taken into account in the consideration of an operation. Furthermore, given the arrival of Riociguat (a stimulator of the soluble guanylate cyclase) and BPA, alternative treatment options with lower risk must be considered.

In our own experience with 1,450 PEAs during the last 
12 years, we performed twenty-one redo PEAs (1.5\%) where patients with pulmonary artery sarcoma were excluded. Three patients were initially operated on in our department and eighteen patients in other centers. In those patients operated on in other centers, the main procedure was described as a thrombectomy of varying degree in ten patients, and as PEA in eight patients. During reoperation in all patients except one, a good visual clearance was achieved. One patient died perioperatively due to persistent right heart failure, yielding a total mortality of $4.8 \%$. Focusing only on patients with a real PEA as first operation, mortality was $12.5 \%$. Comparable mortality numbers are reflected by former reports from San Diego (7.7\%) (6), Cambridge (8.3\%) (5) and are substantially higher from Pavia (40\%) (8). These numbers must be compared to the mortality numbers of first PEAs in high-volume centers $(>100$ PEAs per year) which are in the range of $2 \%$ to $3 \%(9,10)$. Currently in our department, we treat selected patients with residual pulmonary hypertension $(\mathrm{PH})$ after PEA with approved PAH medication and perform additional BPAs if peripherally located target lesions are found in the pulmonary angiography that are not amenable to surgery. In cases of inappropriate first surgery or reembolism and recurrent $\mathrm{PH}$, we indicate redo PEA.

\section{Conclusions}

High-volume PEA centers regularly perform reoperations. Redo PEAs have significantly higher rates of morbidity and mortality $(5,6,8)$. The main indication is $\mathrm{PH}$ because of incomplete clearance during the first operation or reembolism. In our experience, most reoperations are sequelae of inadequate primary operations, underlining the need for centralized treatment of CTEPH patients. This would have a significant effect in reducing the numbers of redo PEAs and would therefore benefit patients with CTEPH and avoid unnecessary additional treatments. With emerging therapies consisting of Riociguat and BPA, further effective treatment modalities for patients with $\mathrm{PH}$ after PEA are now available. The difficult task of decision making belongs to an experienced multidisciplinary CTEPH-team to yield the highest benefit and minimize the risk for the patients.

\section{Acknowledgments}

Funding: None.

\section{Footnote}

Conflicts of Interest: The authors have no conflicts of interest to declare.

Open Access Statement: This is an Open Access article distributed in accordance with the Creative Commons Attribution-NonCommercial-NoDerivs 4.0 International License (CC BY-NC-ND 4.0), which permits the noncommercial replication and distribution of the article with the strict proviso that no changes or edits are made and the original work is properly cited (including links to both the formal publication through the relevant DOI and the license). See: https://creativecommons.org/licenses/by-nc-nd/4.0/.

\section{References}

1. Galiè N, Humbert M, Vachiery JL, et al. 2015 ESC/ERS Guidelines for the diagnosis and treatment of pulmonary hypertension: The Joint Task Force for the Diagnosis and Treatment of Pulmonary Hypertension of the European Society of Cardiology (ESC) and the European Respiratory Society (ERS): Endorsed by: Association for European Paediatric and Congenital Cardiology (AEPC), International Society for Heart and Lung Transplantation (ISHLT). Eur Heart J 2016;37:67-119.

2. Cannon JE, Su L, Kiely DG, et al. Dynamic Risk Stratification of Patient Long-Term Outcome After Pulmonary Endarterectomy: Results From the United Kingdom National Cohort. Circulation 2016;133:1761-71.

3. Ghofrani HA, D'Armini AM, Grimminger F, et al. Riociguat for the treatment of chronic thromboembolic pulmonary hypertension. N Engl J Med 2013;369:319-29.

4. Olsson KM, Wiedenroth CB, Kamp JC, et al. Balloon pulmonary angioplasty for inoperable patients with chronic thromboembolic pulmonary hypertension: the initial German experience. Eur Respir J 2017;49:1602409.

5. Ali JM, Dunning J, $\mathrm{Ng}$ C, et al. The outcome of reoperative pulmonary endarterectomy surgery. Interact Cardiovasc Thorac Surg 2018;26:932-7.

6. Mo M, Kapelanski DP, Mitruka SN, et al. Reoperative pulmonary thromboendarterectomy. Ann Thorac Surg 1999;68:1770-6; discussion 1776-7.

7. Elbadawi A, Hamed M, Elgendy IY, et al. Outcomes of Reoperative Coronary Artery Bypass Graft Surgery in the United States. J Am Heart Assoc 2020;9:e016282. 
8. Merli VN, Vistarini N, Grazioli V, et al. Pavia Experience in Reoperative Pulmonary Endarterectomy. Semin Thorac Cardiovasc Surg 2017;29:464-8.

9. Madani MM, Auger WR, Pretorius V, et al. Pulmonary endarterectomy: recent changes in a single institution's experience of more than 2,700 patients. Ann Thorac Surg

Cite this article as: Guth S, Wiedenroth CB, Mayer E. Pulmonary endarterectomy reoperation: frequency, risk factors and outcomes. Ann Cardiothorac Surg 2022;11(2):166-168. doi: 10.21037/acs-2021-pte-140
2012;94:97-103; discussion 103.

10. Lankeit M, Krieg V, Hobohm L, et al. Pulmonary endarterectomy in chronic thromboembolic pulmonary hypertension. J Heart Lung Transplant 2017. [Epub ahead of print]. 